\title{
Wireless landslide monitoring - triggering factors and dynamic behaviour
}

\author{
C Abancó Worldsensing S.L., Spain \\ J Paretas-Martínez Worldsensing, Spain \\ E Falgàs Worldsensing, Spain \\ J Pérez-Arcas Worldsensing, Spain \\ M Hürlimann Technical University of Catalonia, Spain
}

\begin{abstract}
Monitoring is fundamental for the prediction and analysis of landslide triggering factors and dynamic behaviour and major issues in the hazard assessment and risk mitigation. Wired monitoring systems have traditionally been used in landslide monitoring. However, wireless technologies are escalating in this field as a consequence of their multiple advantages against standard wired systems, such as their versatility and lower power consumption. Wireless monitoring is a perfect solution for the acquisition of data on geological processes in remote areas where power availability is scarce and the position of the sensors is often a critical issue due to the landscape conditions. In this paper, a complete landslide wireless monitoring system is described within the context of a successful case study in the Central Pyrenees, Spain.
\end{abstract}

The Rebaixader constitutes a typical high mountain catchment where landslides and torrential processes occur with a sub-annual frequency. Rainfall is the principal triggering factor of the type of landslides occurring at the Rebaixader (debris flows), but the specific details of the geotechnical mechanisms that originate the events is still not clear. In order to increase the knowledge on the processes occurring at the catchment, it was equipped with a Loadsensing network for the monitoring of triggering factors and a Spidernano Seismic Remote Unit for the acquisition of the ground vibration generated by the moving mass.

The Loadsensing sensor network incorporates seven nodes provided with wireless communication capabilities, showing ultra-low power consumption and long-range communication. Digital, pulse and voltage sensors are connected to these nodes in order to monitor soil water content, soil water potential, snow height, 5-minute rainfall intensity, and air temperature and humidity. The sensor nodes communicate in a multi-hop fashion to deliver the information into a gateway, placed $500 \mathrm{~m}$ away in the line of sight, with two repeaters placed along the line. The gateway offers enhanced computational and storage capabilities, as well as $3 G$ modem communication to the data centre.

Spidernano is a seismic remote unit (SRU) equipped with GPS clock discipline, which is connected to the Gateway via Ethernet cable. It was connected to three $1 D$ geophones recording simultaneously the ground vibration generated by the passage of the debris-flow mass near the geophones. It has a low power consumption $(0.5 \mathrm{~W})$, specially adapted for field campaigns or permanent monitoring.

The recordings revealed that debris-flow occurrence can be detected by ground vibration signal and the approach of the flowing mass can even be detected before the arrival. Data acquired by Loadsensing provided valuable results on the understanding of the failure and post-failure mechanisms such as the infiltration patterns of water into the soil before and during the events. All these achievements are promising results for the application of low power wireless technologies not only for standard landslide monitoring but also for landslide early warning systems. 


\section{Introduction}

Mass movements occur worldwide, especially in mountainous regions. Hazard induced by landslides is a question of concern for people living in endangered areas. Besides being a matter of interest, many uncertainties still exist related to the hazard assessment of mass movements. Monitoring is a valuable tool to understand the mechanisms, frequency of occurrence and the effects of mass movements. Moreover, monitoring systems can be used for early warning or alarm purposes, in order to mitigate the risk. A variety of sensors are being used to identify the approach or the occurrence of dangerous events.

Traditionally, monitoring systems have been deployed in the field using sensors and dataloggers, connected by wires. However, wireless technologies are arising in the field of landslide monitoring and present several advantages over traditional wired systems, such as their versatility and their lower power consumption. Wireless monitoring is applicable for the acquisition of data in remote areas, where power availability is scarce, and the position of the sensors is often a critical issue due to the landscape conditions.

Many different types of mass movements are described in the literature (Cruden \& Varnes 1996; Hungr et al. 2014). Specific monitoring systems are designed for each type of process. The present work is focused on a case study of a monitoring system for debris flows. Debris flows are a type of mass movement consisting of a high density flowing mixture of solid material and water, which often occur in steep torrents (Costa 1984; Johnson \& Rodine 1984). Debris flows are one of the most hazardous geomorphologic processes as they travel at high velocities (several metres per second), and can affect populated areas and infrastructure in mountainous regions, as well as other elements at risk, causing economic losses and even casualties (Jakob \& Hungr 2005). Debris flows occur in many mountainous regions if conditions are favourable. As inherent factors in the catchment, they may be steep slopes and a source of granular unconsolidated sediment to be incorporated into the flowing mass. Rainfall is the most common triggering factor for debris flows.

From the point of view of the initiation mechanism, two types of debris flows can be distinguished: landslide triggered debris flows and in-channel debris flows. The landslide triggered debris flows are events that start with a slope failure. Then, the sliding mass flows into the stream and becomes a flow like motion. Material from the channel is incorporated into the flowing mass by entrainment. In contrast, the in-channel debris flows start inside the torrent when the extremely large water discharge starts to incorporate the loose materials in the channel bed, if the slope is sufficiently steep (Hungr et al. 2005).

There are several existing monitoring systems for debris flows intended to describe three major aspects: (a) initiation, (b) flow dynamics and (c) accumulation. Both the pre-failure conditions (initiation) and post-failure behaviour (flow dynamics) are studied and monitored in the case study presented. Monitoring pre-failure has the intention of studying the triggering conditions (external) and preparing factors of the failure. Monitoring of post-failure behaviour normally has the intention of gathering information on the mechanisms related to the dynamics of the moving mass.

In this paper, a complete debris-flow monitoring system is presented based on wireless, low power technologies from Worldsensing (2015). The system was designed to monitor pre-failure and post-failure conditions. Additionally, some results achieved in the site are presented in order to show the applied capabilities of the wireless, low power technologies in the field of landslide monitoring.

\section{The Rebaixader catchment}

The Rebaixader catchment is located in the central part of the Pyrenean mountain range, between Spain and France, and drains an area of $0.5 \mathrm{~km}^{2}$ into the Noguera Ribagorçana River (Figure 1). The basin is situated in the Axial Pyrenees, where bedrock consists of Paleozoic metamorphic rocks including Devonian slates and phyllites formed during the Hercynian orogeny (Muñoz 1992). Colluvium and granular glacial deposits (tills) cover the bedrock. A large lateral moraine located between 1,425 and 1,710 m a.s.l. plays a major role in the debris-flow activity. A steep accurate scarp in this lateral moraine forms the initiation zone for the debris flows with almost unlimited sediment availability. 
The annual precipitation in the area ranges from 800 to $1,200 \mathrm{~mm}$ and is strongly influenced by the orographic effect (UAB 2004).

Several major factors have supported the selection of the Rebaixader torrent for wireless monitoring purposes: (1) debris-flow monitoring test-site from 2009; (2) no power available; (3) sensors spread all over the torrent - the initiation, transit and accumulation zones (about $1 \mathrm{~km}$ distance); and (4) difficulties to place sensors.

In torrential catchments, other geomorphic processes can occur besides debris flow, i.e. debris floods or rockfalls. Although the Rebaixader monitoring site was installed for the purpose of monitoring debris flows, other types of torrential processes have been identified.

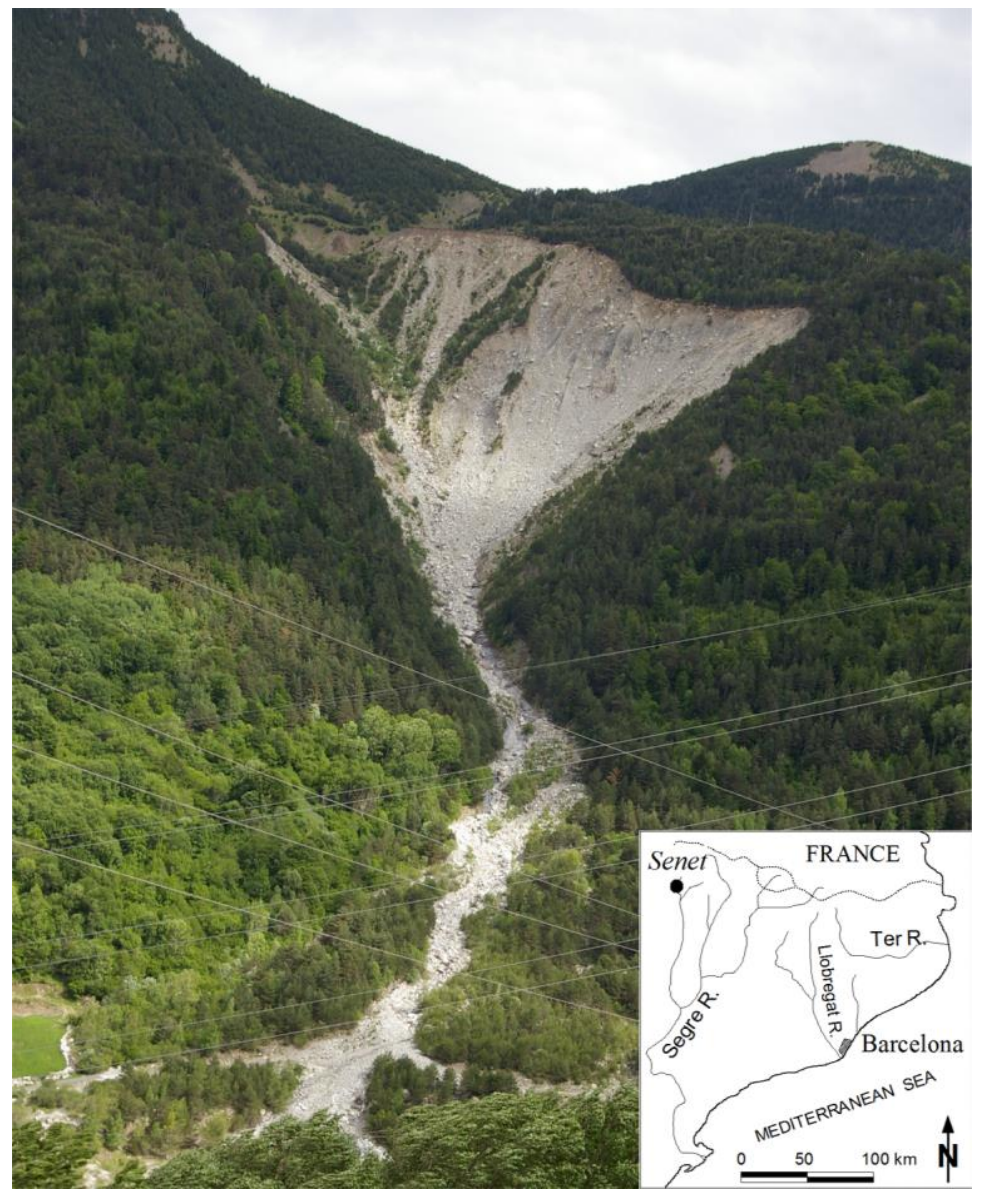

\section{Figure 1 View of the Rebaixader torrent in the Axial Pyrenees. Inset, the location of the nearby village of Senet}

\section{$3 \quad$ Wireless monitoring system}

The monitoring activities at the Rebaixader torrent started in 2009 with the installation of five geophones equipped with signal conditions to simplify the signal, one ultrasonic device, one video camera (for post-failure monitoring), and one meteorological station (for pre-failure monitoring) connected to traditional monitoring systems (wired). Several problems associated with this type of monitoring system have occurred since then: cut wires, need for big solar panels, which were damaged several times, etc. In 2012, the Rebaixader torrent was selected as a test site for installing a wireless, low power monitoring system (Hürlimann et al. 2014; Abancó et al. 2014a).

The Loadsensing wireless monitoring system was installed in 2012 to monitor the pre-failure conditions. Loadsensing dataloggers, called nodes, are connected to meteorological and infiltration sensors measuring at a five-minute sampling rate. The meteorological sensors measure rainfall, air temperature, air relative humidity, atmospherical pressure and snow height. The infiltration stations measure soil water content, soil 
water potential and soil temperature. The sensors are connected to four voltage nodes and three digital nodes, distributed into two main areas: TOP area and SCARP area (Figure 2(a)). TOP is placed in the flat area, over the area where the scarp starts. The SCARP area is placed at the upper part of the scarp. These sensor network devices show ultra-low power consumption (up to 5 years battery life using AA standard cells) and long range communication (200-500 m). The wireless monitoring system is integrated by seven nodes and two repeaters, which communicate in a multi-hop fashion to deliver the information into a gateway (Figure 2). The wireless communication is based on the IEEE802.15.4 protocol at $2.4 \mathrm{GHz}$.

The Spidernano low power seismic recording unit was selected to monitor post-failure conditions. Due to their low power capabilities, it is connected to three 1-D geophones recording continuously at a sampling frequency of $250 \mathrm{~Hz}$. The geophones (Geo5, Geo6 and Geo7) are spread along the torrent channel placed on different conditions: buried in the soil or attached to bedrock. Data from Spidernano is downloaded through an Ethernet port connected to the gateway. The purpose of the geophones is to monitor the dynamic behaviour of the flowing mass when passing by the geophones.

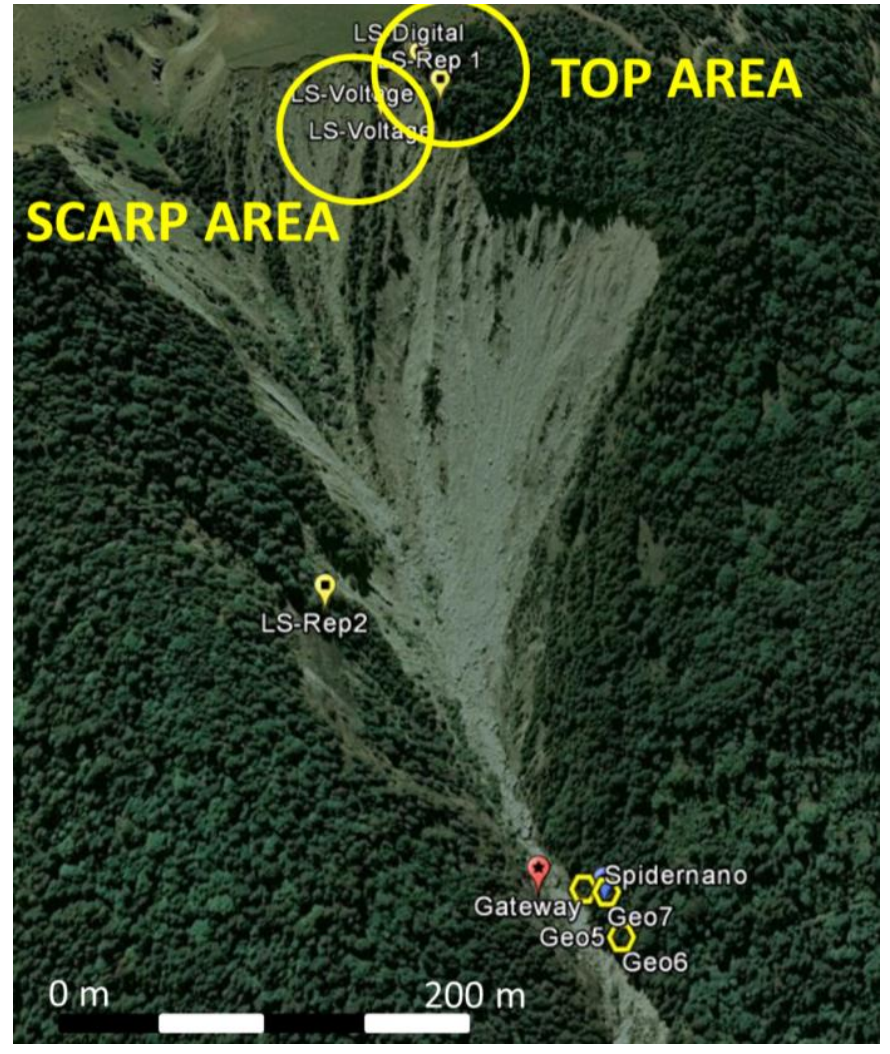

(a)

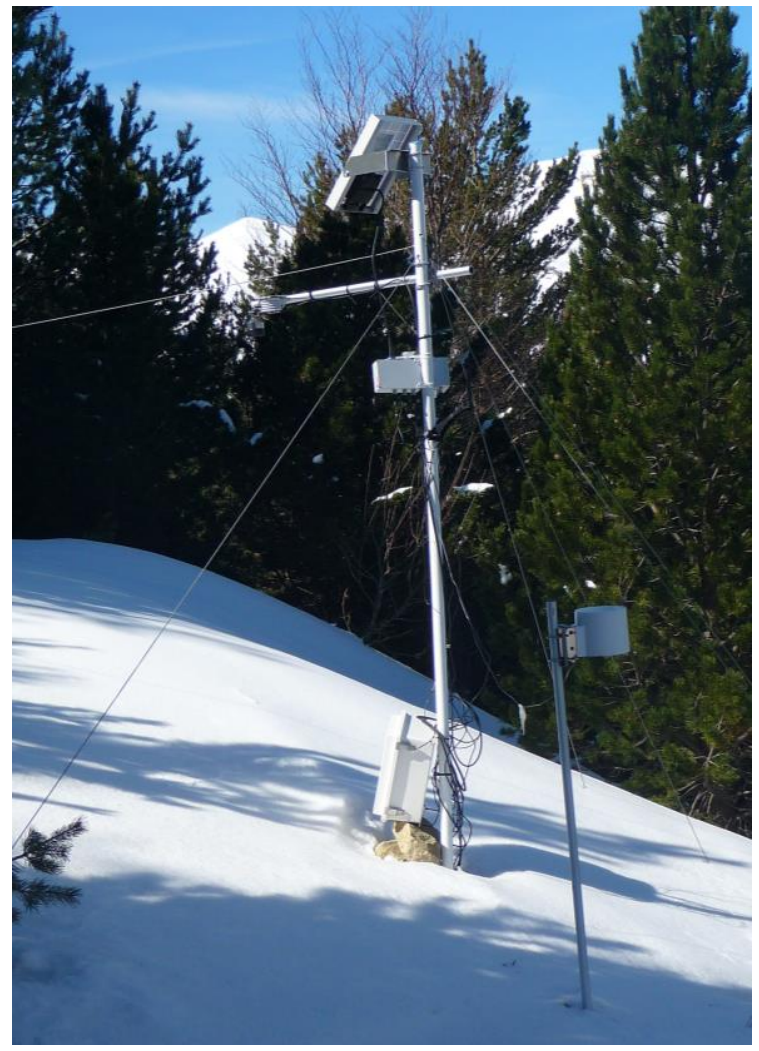

(b)

Figure 2 (a) general view of the location of the Loadsensing nodes, the gateway and the Spidernano; (b) detail of the meteorological sensors and the corresponding nodes, attached to the pole

\subsection{Loadsensing}

Loadsensing is a wireless system with MESH format, one of the most secure wireless solutions on the market. The network installed at the Rebaixader catchment contains seven nodes connected to sensors and two repeaters. A network is a group of nodes with the same ID, security password and they are synchronised themselves.

Data from the sensors is acquired by the nodes and transmitted to the gateway. The communication protocol based in frequency hopping and the temporal synchronisation permits the operation of 1,000 sensors in a network without any interference. All the information transmitted in the network is 
encrypted, some mechanisms to prove the integrity of the messages, as well as the authentication to access to the network, the creation of keys and even the exchange of passwords.

The difference and advantage compared to a classic system is that due to a MESH network, a node is affected (due to disconnection, malfunction etc.) and will remain isolated, minimising the impact of its disappearance in the network (Figure 3(a)). The network will adapt to the new situation dynamically. In classic wired systems, the broken wires or the disconnection could induce a total loss of the system. Each node acts as emitter of its own data but also as a repeater of the neighbour nodes.

The gateway of the network (Figure 3(b)), acts as the time base to the nodes, as well as provides their configuration. The gateway offers enhanced computational and storage capabilities, as well as $3 \mathrm{G}$ modem communication to the remote data centre. Eventually, the data is transmitted periodically to a backend system in a database that provides metadata and has a safe backup strategy. A web-based user interface is also implemented to manage the network remotely. The routing of the information is dynamic and always seeks the best path to the gateway. When a new Loadsensing device is incorporated to the network, a new ID is assigned and receives the information of the temporal and frequency synchronisation from its neighbours. This keeps the network synchronised and correctly working with the new device. This makes it possible to operate several networks in the same place without interaction between them. A device with an ID that does not correspond to the network will keep waiting to receive a message with the temporal and frequency configuration and, therefore, will not be able to send data.

The devices communicate periodically, following the programming. Additionally, to improve the robustness of the communications, Loadsensing uses several channels of communications that exist at a $2.4 \mathrm{GHz}$ frequency, following a technique called Channel Hopping, which permits avoiding interferences. Each package of sent data from a node to another node will be sent through a different channel, searching the best available channel depending on the level of interference observed in the different channels. All the devices of the network share the same time base, this means that each node transmits, listens or sleeps during the same time windows assigned. Each time window of data sending has a length of short milliseconds, which allows the devices to keep sleeping the most of the time and only be active in the window of data sending. This creates very secure networks, robust and of very low power. Mechanically, the devices are also very robust. They are protected with the IP67 encapsulation, protected from rainfall, impacts, thunders, dust, etc.

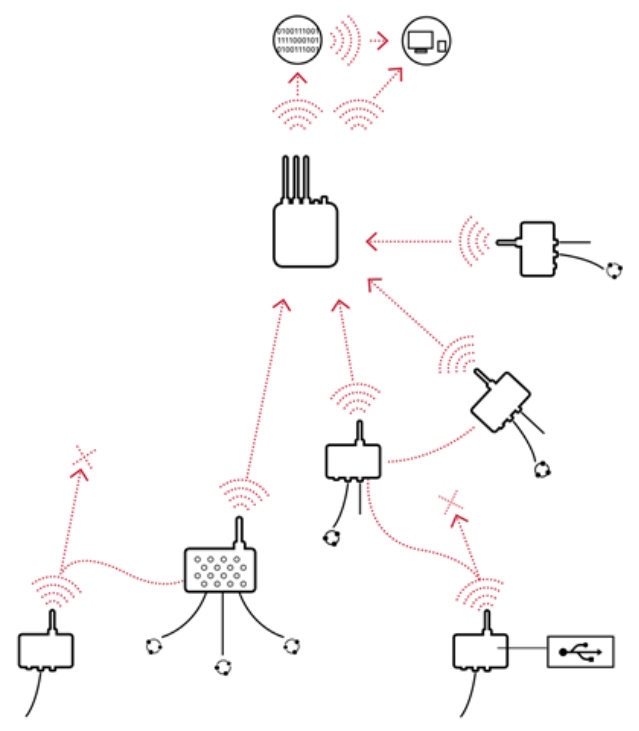

(a)

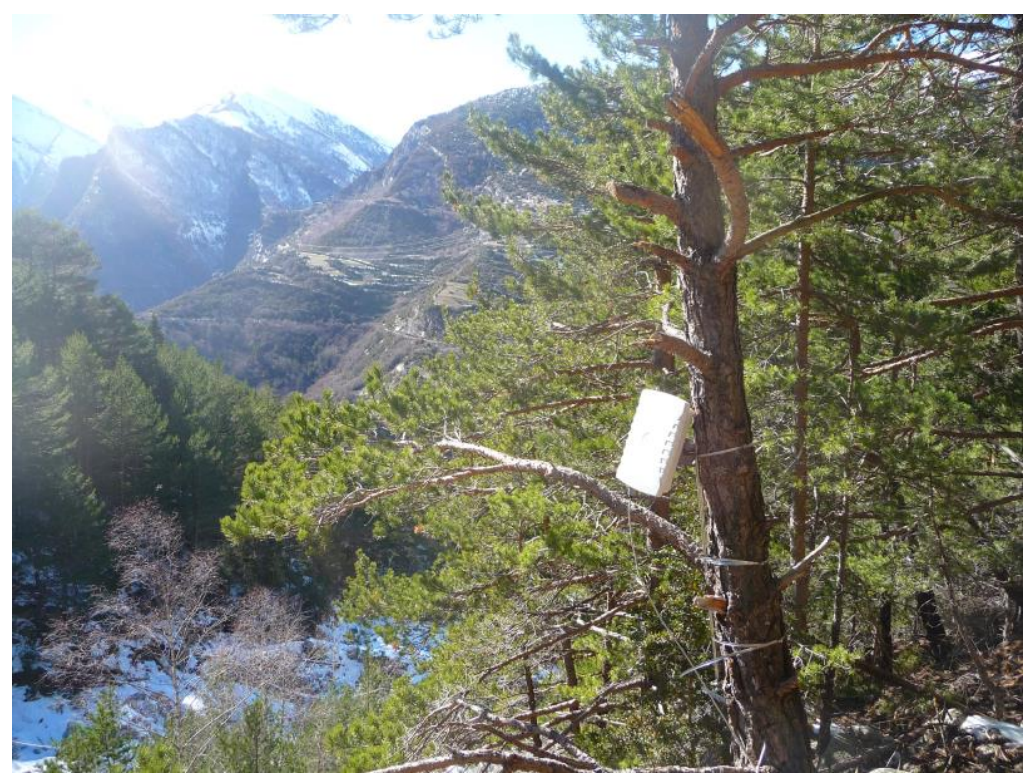

(b)

Figure 3 (a) schematic view of Loadsensing networks architecture; (b) view of the gateway installed at the Rebaixader catchment 


\subsection{Spidernano}

Spidernano is a seismic remote unit (SRU) especially designed to register seismic signals under the most harsh weather conditions and demanding environments (Figure 4). The units offer the capacity of command and control as well as remote operation. Spidernano is compact, light and robust and prepared for long term deployments.

The SRU is a data acquisition system with three simultaneous sampling channels. At the Rebaixader catchment, three 1D geophones are connected (Geo5, Geo6 and Geo7). It delivers proficiency resolution with high dynamic range of $143 \mathrm{~dB}$ at $2 \mathrm{~ms}$, and it has a low power consumption allowing for continuous operation on battery for several weeks. Each unit delivers 24 bits $A / D$, and a disciplined clock and GPS sync. Several sampling frequencies are available in the SRU: 50,100, 250 and $500 \mathrm{~Hz}$. The system offers multiple communication capabilities including Ethernet or WiFi/3G (optional).

A Web server especially developed to support field operations is integrated on the SRU. The interface Web allows operating the units in a direct form. It does not require additional software to operate the units; connecting a computer to the SRU connector the internal web application to the unit allows configuration of the unit, as well as downloading and accessing the data registered in real-time.

In the case of an event, a specific trigger data recording file is initiated owing to short-term average/long-term average (STA/LTA) or level triggers. Each unit offers up to $32 \mathrm{~Gb}$ of internal data storage in miniSeed format that allow storage up to six months of data for post processing recovery. Memory mode is a circular buffer.

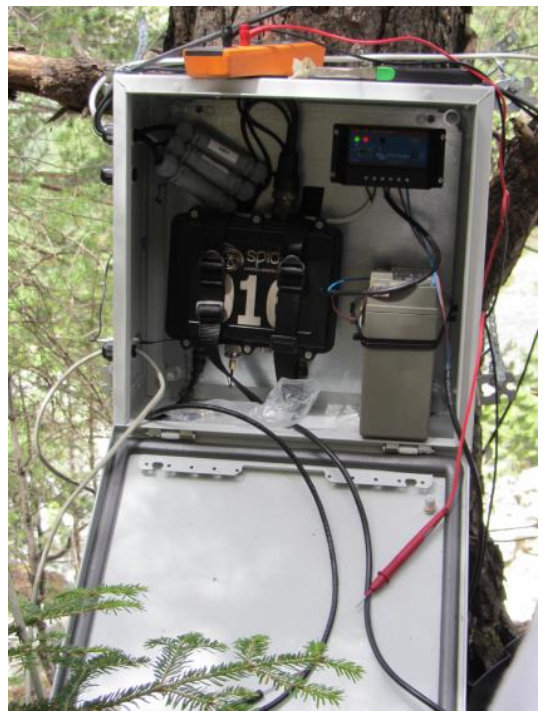

(a)

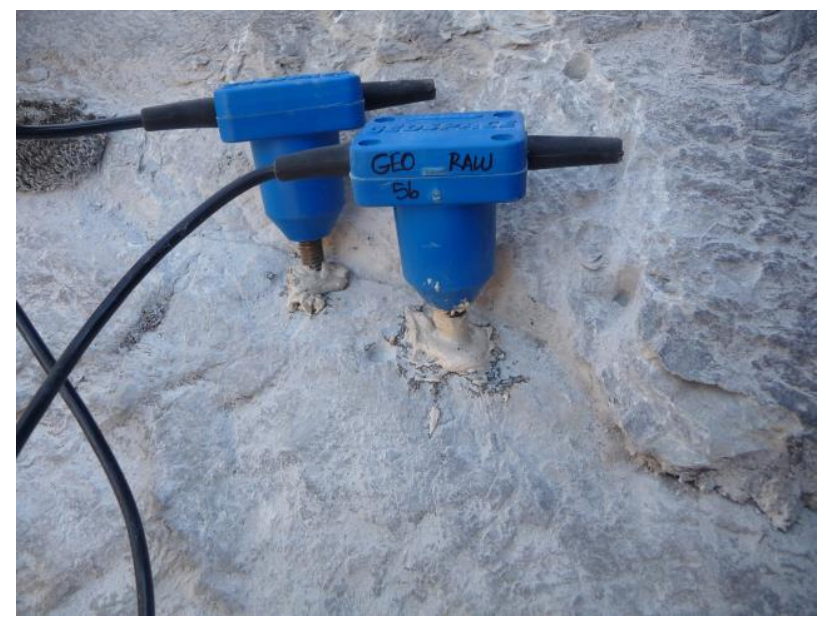

(b)

Figure 4 (a) view of the Spidernano inside the box that contains the battery and solar regulator; (b) detail of the geophones attached to the bedrock

\section{$4 \quad$ Results achieved}

\subsection{Triggering conditions}

The combined analysis of all the sensors installed at the catchment provided relevant information on the mechanisms of the failure and post-failure conditions. A detailed analysis of two events that occurred in 2013 is presented (Figure 5). The selected events show different patterns for the infiltration, associated to the triggering conditions of the event (Abancó et al. 2014b).

The first pattern (Figure 5(a)) corresponds to a debris flood. The rainfall starts and the torrential event is triggered, as it can be identified from the vibration of the geophone. However, the increase of the volumetric water content (VWC) in the soil does not take place either before or during the event, but after 
the event. The infiltration of the water into the soil is slow and the effect that it has on the occurrence of the debris flood is unclear.

The second pattern (Figure $5(\mathrm{~b})$ ) corresponds to a debris flow event. The rainfall starts and the event takes place a few moments after. The infiltration of the water into the soil is fast and it is simultaneous to the rainfall.

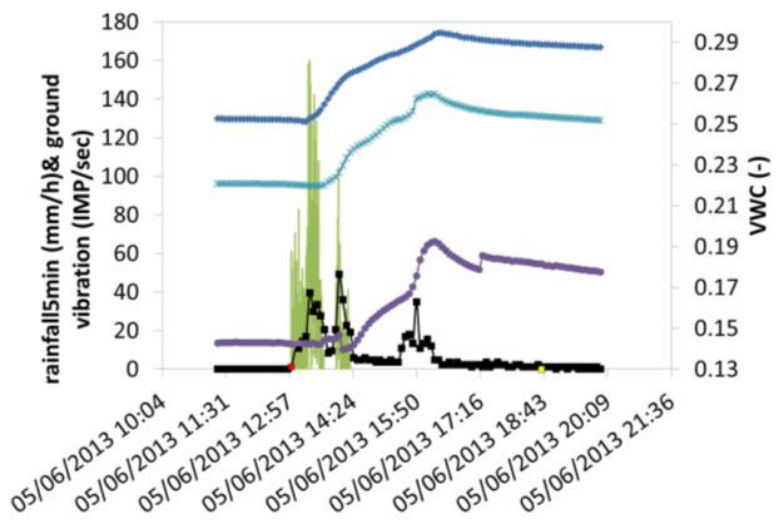

(a)

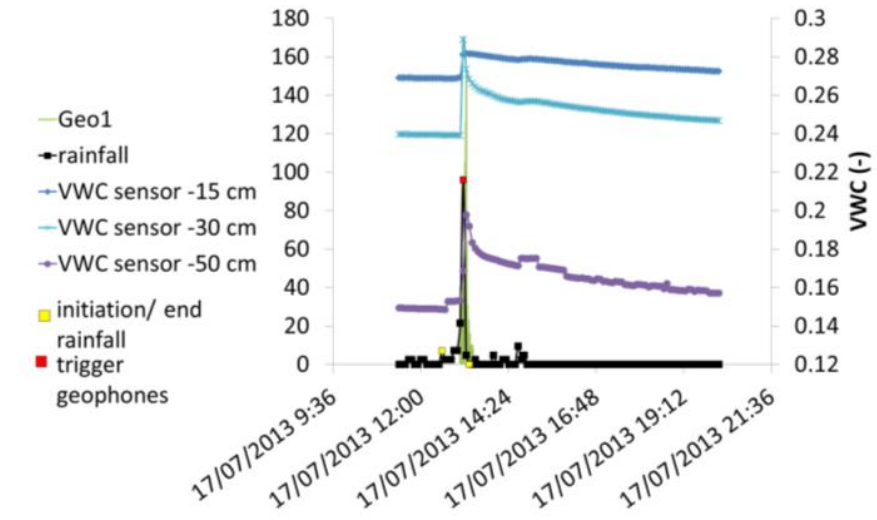

(b)

Figure 5 VWC sensors of Loadsensing network, geophone data and initiation/end of rainfall corresponding to

(a) debris flood occurred at the Rebaixader catchment (5 June 2013); and (b) debris flow occurred at the Rebaixader catchment (17 July 2013)

\subsection{Dynamic behaviour}

The ground vibration recorded by Spidernano during the events shows different phases that define the progression of the flowing mass over time. Geo5 is the geophone showing this distinction better. An example of a debris flow event occurred on the 4 July 2012. Data from Geo5 (channel 1 of Spidernano) shows four different phases (Figure 6).

Phase $A$ (P.A) is a pre-event phase, characterised by stationary low values of ground velocity signal and also low stage measured at the ultrasonic device. Typical values of the ground velocity for Phase $A$ are less than $0.005 \mathrm{~mm} / \mathrm{s}$ and are about 100 times lower than the highest value of the signal during debris flows. These values represent between $\sim 1 \%$ (for debris flows).

Phase B (P.B) is characterised by a rapid increase of the values of the GVS as well as the flow stage and corresponds to the passage of the debris-flow main front(s). The GVS records of this phase are the highest ones of the event, up to $1.6 \mathrm{~mm} / \mathrm{s}$ (at Geo7). The duration of Phase B was short compared to the other phases (only $\sim 40 \mathrm{~s}$ ).

Phase C (P.C) is defined by GVS values lower than the flow front, but some peaks are still visible as well as punctual flow-depth increases. This phase is related to the passing of the main body of the flow. This is characterised by high values of vibration compared to Phase A and Phase D, although lower than Phase B. Typical values are of some tenths of $\mathrm{mm} / \mathrm{s}$ for debris flows. The duration of this phase was $\sim 100 \mathrm{~s}$.

Phase D (P.D) includes a gradual decrease of GVS and stage measurements back to the pre-front values of Phase A. However, some small increments can still be observed. This last phase is interpreted as corresponding to the flow tail. It is characterised by low values of vibration but some peaks could be observed. An explanation of these peaks may be related to the passing of some boulders or small waves in spite of the global decrease of vibration. 
a)
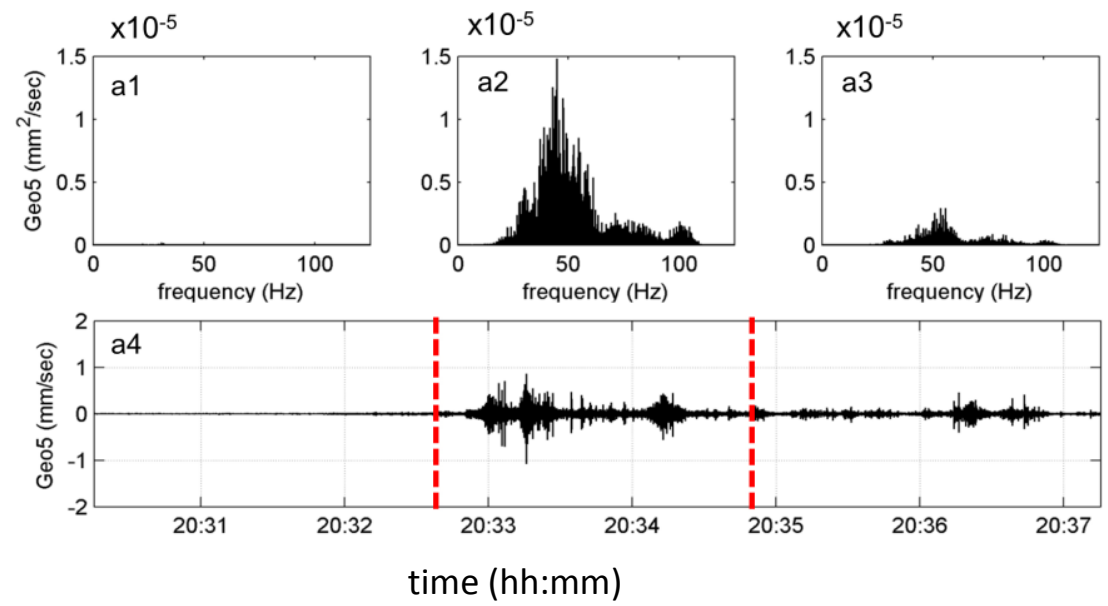

\section{Figure 6 Ground vibration signals from Geo5 recorded previously and during the debris flow that occurred on 4 July 2012. Time series (a4) and power spectra (a1 to a3) are shown respectively. The dashed lines indicate the limits of the 2.3 min intervals. Each power spectra plot corresponds to the time interval below}

\section{Conclusion}

The results achieved in the Rebaixader catchment with the wireless, low power solutions from Worldsensing provide an example of natural hazards monitoring incorporating new technologies. Loadsensing network provided information on the pre-failure conditions, showing different patterns of water infiltration into the soil, which are associated with different types of events. Data acquired by Spidernano showed that debris flows can be detected by ground vibration signal and the approach of the flowing mass can be detected even before the arrival.

\section{Acknowledgement}

This research was funded by the Spanish Ministry MINECO contract CGL2011-23300 (project DEBRISTART).

\section{References}

Abancó, C, Hürlimann, M \& Moya, J 2014a, 'Analysis of the ground vibration produced by debris flows and other torrential processes at the Rebaixader monitoring site (Catalan Pyrenees, Spain)', Natural Hazards and Earth System Science, vol. 14, pp. 929-943.

Abancó, C, Hürlimann, M \& Moya, J 2014b, 'Towards a debris-flow warning system based on hydrological measurements of the triggering conditions. A study of El Rebaixader catchment (Central Pyrenees, Spain)', Geophysical Research Abstracts, vol. 16.

Costa, JE 1984, 'Physical geomorphology of debris flows', in JE Costa \& PJ Fleisher (eds), Developments and applications of geomorphology, Springer-Verlag, Berlin, pp. 268-317.

Cruden, DM \& Varnes, DJ 1996, 'Landslide types and processes', in KA Turner \& RL Schuster (eds), Landslides: investigation and mitigation, Transport Research Board Special Report, vol. 247, pp. 36-75.

Hungr, O, McDougall, S \& Bovis, M 2005, 'Entrainment of material by debris flow', in M Jakob \& O Hungr (eds), Debris-flow Hazards and Related Phenomena, Springer, Berlin, pp. 135-158.

Hungr, O, Leroueil, S \& Picarelli, L 2014, 'The Varnes classification of landslide types, an update', Landslides, vol. 11, no. 2, pp. 167-194.

Hürlimann, M, Abancó, C, Moya, J \& Vilajosana, I 2014, 'Results and experiences gathered at the Rebaixader debris-flow monitoring site, Central Pyrenees, Spain', Landslides, vol. 11, no. 6, pp. 939-953.

Jakob, M \& Hungr, O 2005, Debris-flow Hazards and Related Phenomena, Springer, Berlin.

Johnson, AM \& Rodine, JR 1984, 'Debris flow', in D Brunsden \& DB Prior (eds), Slope Instability, John Wiley and Sons, Inc., New York, NY, pp. 257-361.

Muñoz, JA 1992, 'Evolution of a continental collision belt: ECORS-Pyrenees crustal balanced cross-section', in KR McClay (ed.), Thrust Tectonics, Chapman \& Hall, pp. 235-246.

UAB 2004, Universitat Autònoma de Barcelona, Climatic Atlas of Catalonia, Barcelona, viewed 22 July 2012, http://www.opengis. uab.cat/acdc/ 
Wordsensing 2015, Wordsensing, Barcelona, viewed 1 June 2015, http://www.worldsensing.com/ 